\title{
Percepção da família sobre a assistência a pessoas com hipertensão arterial que foram a óbito*
}

\author{
The family's perception regarding the care to people with hypertension who died
}

Percepción de la familia sobre la atención a personas con hipertensión arterial fallecidas

Mayckel da Silva Barretoํ, Regina Lúcia Dalla Torre Silva², Maria Angelica Pagliarini Waidman³, Sonia Silva Marcon ${ }^{4}$

\footnotetext{
* Recorte do Projeto "Avaliação da atenção à hipertensão Arterial na macroregião noroeste do Paraná: doenças cérebro-vasculares como evento sentinela" apoiado pelo CNPq - Edital Universal. Processo: 402441/2005-2.

${ }^{1}$ Enfermeiro. Discente do Programa de Pós-Graduação em Enfermagem da Universidade Estadual de Maringá (PSE/UEM), nível Mestrado. Enfermeiro da Secretaria Municipal de Saúde de Mandaguari. Mandaguari, PR, Brasil. E-mail: mayckelbar@gmail.com.

${ }^{2}$ Enfermeira, Mestre em Saúde Coletiva. Discente do PSE/UEM, nível Doutorado. Professora Assistente do Departamento de Enfermagem da UEM. Maringá, PR, Brasil. E-mail: rldtorre@uem.br.

3 Enfermeira, Doutora em Enfermagem. Professora Adjunta do Departamento de Enfermagem da UEM. Maringá, PR, Brasil. E-mail: angelicawaidaman@hotmail.com.

${ }^{4}$ Enfermeira, Doutora em Filosofia da Enfermagem. Professora Associada do Departamento de Enfermagem da UEM. Maringá, PR, Brasil. E-mail: soniasilva.marcon@gmail.com.
}

\section{RESUMO}

O objetivo deste estudo foi identificar como as famílias de pessoas com hipertensão que foram a óbito em decorrência de doenças cerebrovasculares perceberam a assistência prestada aos mesmos na atenção básica. Os dados foram coletados em janeiro e fevereiro de 2008 em 16 municípios da macrorregião noroeste do Paraná, junto a familiares de 42 pessoas, a partir de entrevista semiestruturada. Os resultados mostraram que as famílias qualificam a assistência prestada na atenção básica considerando visitas domiciliares realizadas com frequência e a presença do médico e pelo apoio recebido dos profissionais na realização dos cuidados. Entretanto, identificaram a demora nos encaminhamentos para exames e consultas com especialistas e a indiferença de alguns profissionais durante a assistência como principais problemas. Os achados podem contribuir para a definição de ações assistenciais a serem adotadas pelos serviços de saúde, objetivando a melhora do acompanhamento à pessoa com hipertensão e sua família.

Descritores: Hipertensão; Família; Saúde da Família; Enfermagem Familiar.

\section{ABSTRACT}

The objective of this study was to identify how families of people with hypertension who died due to cerebrovascular diseases realize the care they received at the primary healthcare service. Data collection was performed between January and February of 2008 in 16 cities covered by the macro-region of northwest Paraná, through a semi-structured interview with family members of 42 individuals. Results showed that families evaluated the primary healthcare based on frequent home visits and the presence of the physician, as well as the support received from healthcare professionals. The main problems identified, according to the interviewees, were the delay in referring patients for examinations and appointments with a specialist, as well as the indifference of some professionals. The findings may contribute with the establishment of health care actions to be adopted by health services, with the purpose to improve the follow up of individuals with hypertension and their families.

Descriptors: Hypertension; Family; Family Health; Family Nursing.

\section{RESUMEN}

Se objetivó identificar el modo en que las familias de personas con hipertensión que fallecieron por consecuencia de enfermedades cerebrovasculares percibieron la atención ofrecida en la atención básica. Datos recolectados en enero y febrero 2008 en macro-región noroeste de Paraná-BR de familiares de 42 personas, utilizándose entrevista semiestructurada. Los resultados expresaron que las familias califican la asistencia brindada en la atención básica a partir de las visitas domiciliarias, cuando estas son realizadas con frecuencia y con presencia del médico; y por el apoyo recibido de los profesionales en la realización de cuidados. Sin embargo, identifican la demora en las derivaciones para exámenes y consultas con especialistas y la indiferencia de algunos profesionales durante la atención como principales problemas. Las conclusiones pueden contribuir a definir acciones asistenciales a ser adoptadas por los servicios de salud, apuntando a la mejora del seguimiento de las personas con hipertensión y sus familias.

Descriptores: Hipertensión; Familia; Salud de la Familia; Enfermería de la Familia. 


\section{INTRODUÇÃO}

A Estratégia Saúde da Família (ESF) está pautada na visão ativa da intervenção em saúde, ou seja, não esperar somente a busca espontânea da população aos serviços de saúde para se intervir, desta forma, busca-se reorganizar a demanda. Além disso, reforçam-se as concepções de integração com a comunidade e a família, nas diversas fases do ciclo vital, bem como o enfoque na atenção integral, evitando, assim, ações reducionistas em saúde, centradas somente, na intervenção biológica, médica e individual. Neste contexto, há uma indução do governo brasileiro para que o setor saúde, por meio da qualificação profissional e da corresponsabilização pelo cuidado prestado, reconstrua a produção em saúde ${ }^{(1)}$.

Atualmente as equipes multiprofissionais da ESF, em decorrência das transformações na incidência e prevalência das doenças, bem como nas principais causas de morte(2), atuam cada vez mais com famílias que convivem, no mínimo, com um de seus membros com Doenças Crônicas (DC). Entre os agravos crônicos à saúde destaca-se a Hipertensão Arterial (HA) um dos principais fatores de risco para o desenvolvimento de complicações renais, doenças cardíacas e cerebrovasculares, representando, portanto, altos custos médicos e socioeconômicos, decorrentes principalmente das complicações que a acompanha ${ }^{(3-4)}$.

O número estimado de indivíduos com $\mathrm{HA}$ no Brasil é de aproximadamente 18 milhões. Inquéritos populacionais em cidades brasileiras nos últimos 20 anos apontam uma prevalência de HA acima de $30 \%$, com maior frequência entre os homens ${ }^{(4)}$. Um estudo de revisão sistemática quantitativa que analisou 44 artigos de 35 países, publicados entre 2003 e 2008, revelou uma prevalência global de HA na faixa de 37,8\% em homens e $32,1 \%$ em mulheres ${ }^{(5)}$, próximo a valores encontrados no Brasil. Pesquisa recente do Ministério da Saúde apontou que a HA atinge $23,3 \%$ da população brasileira, no entanto o diagnóstico se torna mais comum com o avançar da idade, acometendo cerca de $8 \%$ dos indivíduos entre os 18 e os 24 anos de idade e mais de $50 \%$ na faixa etária acima dos 55 anos de idade ${ }^{(6)}$.

Estes números e a preocupação com a longevidade do indivíduo e sua qualidade de vida revelam a importância de se desenvolver um trabalho voltado para a promoção, prevenção e redução das DC. Neste sentido, a organização e a sistematização do atendimento a grupos populacionais específicos, como por exemplo, às pessoas com hipertensão, deve ocorrer de forma diferenciada nas Unidades Básicas de Saúde (UBS) ${ }^{(7)}$. Assim, frente à magnitude da doença e com o objetivo de reduzir a morbi-mortalidade associada a HA e ao Diabetes Mellitus (DM), o Ministério da Saúde implantou em 2002 o Plano de Reorganização da Atenção à Hipertensão Arterial e ao Diabetes Mellitus, o qual prevê acompanhamento e avaliação dos impactos na epidemiologia dessas doenças, decorrentes de ações integradas, como por exemplo, o acesso ao tratamento clínico, assistência farmacêutica e promoção à saúde ${ }^{(8)}$.

Acredita-se que com a mudança do paradigma da organização e da implementação da assistência primária, seja alcançado um atendimento diferenciado aos indivíduos com hipertensão e diabetes. Deste modo, o acompanhamento especializado e qualificado deveria ser percebido também pelos membros da família, pois em última instância, esses necessitam ser inseridos como co-participantes do plano assistencial do indivíduo, influenciando sobremaneira na mudança dos hábitos de vida de seus familiares. No entanto, estudos revelam que o sistema de saúde ainda não sofreu as transformações esperadas, e em muitos casos não tem correspondido às necessidades da população, pois a assistência prestada pelas equipes continua centrada na doença, no indivíduo e na cura, sendo que muitas vezes as ações são realizadas sem o planejamento adequado(9-10).

Além disso, estudos que versem sobre a assistência básica ofertada ao indivíduo com DC e sua família após o óbito são escassos, porém de suma importância, pois conhecendo suas necessidades, os serviços de saúde podem reformular as ações assistenciais, voltando-as para os interesses da família, levando o enfermeiro a desenvolver estratégias de intervenção mais eficazes no acompanhamento dos doentes crônicos e seus familiares. Diante do exposto, visando contribuir com a ampliação do conhecimento e qualificação da atenção à saúde na atenção básica, o objetivo deste trabalho foi identificar como as famílias de pessoas com hipertensão que foram a óbito em decorrência de doenças cerebrovasculares, perceberam a assistência prestada aos mesmos na atenção básica.

\section{METODOLOGIA}

Estudo descritivo de natureza qualitativa realizado no âmbito da macro-região noroeste do estado do Paraná. Trata-se de um recorte do projeto de pesquisa intitulado "Avaliação da atenção à Hipertensão Arterial na macro-região noroeste do Paraná: Óbitos por doenças cérebro-vasculares como evento sentinela". 
A macro-região noroeste do Paraná é composta por 115 municípios organizados em cinco Regionais de Saúde (RS). Рara a realização deste estudo os municípios foram divididos em cinco grupos de acordo com o porte populacional (40 municípios com menos de 5.000 habitantes; 40 municípios com população de 5.000 a 10.000 habitantes; 20 municípios com população de 10.000 a 20.000 habitantes; nove municípios com população de 20.000 a 60.000 habitantes e seis municípios com população superior a 60.000 habitantes). Em seguida, foi realizado um levantamento no Datasus dos óbitos ocorridos na faixa-etária de até 64 anos, por doenças cerebrovasculares num período de cinco anos (1998-2002), segundo RS e município de residência e calculou-se o coeficiente de mortalidade por estas doenças, a partir dos dados do IBGE.

De posse destas informações, foram incluídos no estudo os municípios sede de regionais de saúde, um município que tinha mais de 80.000 habitantes e os dois com maior coeficiente de mortalidade em cada um dos cinco grupos totalizando, assim, 16 municípios a serem incluídos no estudo. Para a seleção dos casos a serem incluídos no estudo, considerou-se a totalidade dos óbitos ocorridos nestes municípios no período de $1^{\circ}$ de janeiro a 31 de dezembro de 2006, em indivíduos com até 64 anos por diagnósticos referentes aos códigos 160 e 169 do CID 10.

Os endereços dos entrevistados foram disponibilizados pelas Secretarias Municipais de Saúde. Para a localização das famílias foram realizadas até três tentativas, sendo os familiares procurados inclusive em seus locais de trabaho. No período em questão ocorreram 69 óbitos que atenderam aos critérios de inclusão, porém só foram localizados familiares de 43 indivíduos e em um caso houve recusa do familiar em participar do estudo.

Os informantes, portanto, foram familiares de 42 indivíduos que foram a óbito, residentes em 16 municípios da macro-região noroeste do estado do Paraná. A coleta de dados ocorreu nos meses de janeiro e fevereiro de 2008, por meio de entrevista semiestruturada, utilizando-se um roteiro elaborado a partir dos objetivos do estudo e de forma a valorizar a opinião dos familiares, com questões sobre o perfil sociodemográfico e sobre a assistência recebida pelo paciente na atenção básica nos seis meses anteriores ao óbito, bem como sobre a percepção relacionada ao acompanhamento/assistência, realizada pela equipe de Saúde da Família após o óbito do familiar. As entrevistas tiveram uma duração média de 30 minutos e sempre que houve anuência do familiar, foram gravadas.

Os dados foram submetidos à análise de conteúdo na modalidade temática, utilizando como referencial metodológico $\operatorname{Bardin}^{(10)}$, seguindo-se as etapas préestabelecidas, que incluiu a pré-análise com leituras flutuantes e intensivas, a exploração do material com categorização por agrupamento conforme semelhanças e o tratamento dos dados, que se processou a partir da análise da comunicação objetiva e subjetiva desse material, utilizando-se procedimentos sistemáticos para compreender o conteúdo expresso nas falas dos familiares ${ }^{(11)}$. Na análise dos discursos emergiu a categoria central: Assistência à pessoa com hipertensão na atenção básica: Como a família a reconhece, composta por duas subcategorias - Qualificadores da atenção primária na percepção da família e (Des)qualificadores da assistência na atenção básica: Perspectiva da família.

O desenvolvimento do estudo ocorreu em conformidade com o preconizado na resolução 196/96 do Conselho Nacional de Saúde e seu projeto foi aprovado pelo Comitê Permanente de Ética em Pesquisa com Seres Humanos da Universidade Estadual de Maringá (Parecer $n^{\circ}$ 085/2006). Todos os participantes assinaram o Termo de Consentimento Livre e Esclarecido (TCLE) em duas vias e para garantir o seu anonimato, as falas estão identificadas apenas com a posição familiar do informante em relação ao indivíduo que foi a óbito.

\section{RESULTADOS E DISCUSSÃO}

\section{Características da população estudada}

A maioria dos informantes deste estudo, familiares de pessoas que foram a óbito por doenças cerebrovasculares, era do sexo feminino (74,2\%), encontrava-se na faixa etária entre 51 a 60 anos (46,1\%) ou de 61 a 70 anos (23,1\%), e ocupavam a posição de esposas $(71,4 \%)$, filhas $(14,3 \%)$ ou irmãs $(11,9 \%)$. Perfil semelhante foi observado em outra pesquisa com cuidadores familiares ${ }^{(2)}$.

Os arranjos domésticos dos indivíduos que foram a óbito, considerando o número de pessoas morando na mesma casa, podem ser considerados pequenos, pois em quase metade dos casos (48,3\%) moravam no máximo três ou quatro indivíduos no mesmo domicílio. A presença de outros membros com DC foi frequente, sendo a HA a mais prevalente (58,3\%). Contudo, apesar de um dos familiares ter falecido em decorrência da HA e de, em sua maioria, os membros doentes utilizarem medicamento de uso contínuo (78,6\%), grande parte deles não realizava exercícios físicos e nem atividades de lazer (64,3\%), revelando a necessidade de estas pessoas serem acompanhadas mais de perto pela equipe de saúde, assim como serem sensibilizadas sobre as características e importância de 
seguir corretamente o tratamento, visto que seu familiar faleceu precocemente devido aos agravos da HA.

Com estes dados infere-se que, mesmo tendo um de seus membros falecido por complicações decorrentes da HA, as famílias continuam não realizando cuidados de prevenção/promoção da saúde, fato que pode estar relacionado a duas questões: falta de sensibilização relacionada a doença e/ou; descuido do serviço de saúde, que ao ter um cliente da família ido a óbito por problemas hereditários e modificáveis, deveria realizar um acompanhamento diferenciado e constante à família, já que um dos princípios da ESF é identificar as áreas de risco para a saúde da população e acompanhá-la em suas necessidades individuais e coletivas ${ }^{(9)}$.

Desta maneira, não se pode negar que a ampliação da cobertura dos serviços básicos de saúde, proporcionada pela implantação da ESF, melhorou o acesso da população à assistência primária, permitindo, entre outros avanços, a criação de vínculo entre os usuários e a Equipe de Saúde, o que favorece o acompanhamento sistemático e o incremento das atividades de promoção à saúde e prevenção de agravos ${ }^{(10)}$. Porém, no presente estudo ficou evidente que as equipes de saúde precisavam encontrar outros meios para sensibilizar a população, que não apenas o repasse infundado de informações, pois ao serem questionados sobre as orientações que a equipe da ESF fornecia aos pacientes que foram a óbito, constatou-se que dos familiares que souberam responder a este respeito $(77,4 \%)$, a maioria fez referência ao uso da medicação (87,5\%); necessidade de fazer dieta e os alimentos que deveriam ser evitados (79,2\%); necessidade de praticar exercícios físicos $(58,3 \%)$ e os malefícios do uso da bebida alcoólica (52,0\%) ou do cigarro (48,0\%).

Assim, embora apenas 36,0\% tenham referido que seus familiares foram informados sobre a importância de manter o peso adequado e $29,2 \%$ estimulados a participarem de atividades de grupo na unidade, constata-se que de forma geral, os indivíduos haviam recebido informações relacionadas ao tratamento da HA, no entanto isto não foi capaz de evitar o óbito precoce, apontando a existência de uma lacuna entre a orientação ofertada pela equipe de saúde e sua efetiva aplicabilidade.

\section{Assistência à pessoa com hipertensão na atenção básica: como a família a reconhece}

As famílias, de um modo geral, reconheceram a assistência prestada a seu familiar com HA nos seis meses que antecederam o óbito, a partir das visitas domiciliares, as quais eram realizadas para a maior parte dos sujeitos.

Tal constatação pode ser apreendida como positiva, uma vez que a visita domiciliar, no contexto da ESF é considerada fundamental por inserir os trabalhadores da equipe de saúde no espaço domiciliar, gerando uma possibilidade privilegiada para o desenvolvimento do diálogo e produção de saberes, por meio de atividades educativas em saúde, que podem ser desenvolvidas, com base no conhecimento construído na relação trabalhadores/usuários dos serviços de saúde e familiares $^{(12)}$.

\section{Qualificadores da atenção primária na percepção da família}

Algumas famílias tinham uma percepção positiva em relação às visitas, sendo a continuidade e periodicidade descritas como aspectos qualificadores da assistência:

Recebíamos visitas deles (equipe da ESF), eles vinham sempre, era uma vez por mês, olhavam a pressão e os encaminhamentos da hemodiálise, antes não tinha isso (Filha). Vinha a moça (agente comunitária de saúde) falar para ele que tinha reunião ali no Centro Catequético, para ele ir pegar a receita, ela sempre vinha avisar a data dele ir ao médico, elas sempre atendiam bem (Filha). Eles vinham sempre, quase todo mês, mas nos últimos três anos eles vinham a cada 15 dias para trocar a sonda da urina, ele não precisava sair de casa (Neta).

Para os familiares, o acompanhamento realizado pelas equipes da ESF, entendido a partir das visitas domiciliares, foi percebido como bom, pois a presença dos profissionais de saúde no domicílio representa uma forma diferenciada de assistência e, acima de tudo, melhor do que aquela que recebiam anteriormente, a qual era focada na doença e realizada em instituições de saúde, como os centros de saúde e hospitais.

Constata-se ainda que alguns familiares se mostraram satisfeitos com a assistência prestada pelos profissionais da ESF, pelo fato de além do cuidado biológico dispensado a seu familiar doente, com disponibilização de materiais médicohospitalares de consumo imediato, também ofereciam apoio psicoemocional:

Tinha acompanhamento, o médico vinha a cada oito dias, vinha em casa o médico da família e olhava se tinha ferida, por causa de ficar na cama. Eles cuidavam de tudo, as moças vinham e faziam 
todo o tratamento, fazia tudo, por último era eles que davam a maior força (Filha).

Eles vinham, qualquer dúvida tinha um telefone de acesso para ligar para eles, e as moçinhas, aquelas ACS, passavam direto, traziam pomada, traziam gazes... (Filha).

Ah eu achava bom! Porque elas vinham ver ele, medicava, fazia curativo e sempre com muito respeito (Nora).

A qualidade dos serviços públicos de saúde é um desafio aos gestores, técnicos e todos os profissionais envolvidos no processo de trabalho. Contudo, a capacidade individual e coletiva, se bem geridas, podem originar produtos que satisfazem as necessidades dos usuários. Estudo realizado em Recife (PE), com 591 usuários do SUS revelou que o "respeito à intimidade" e o "sigilo das informações pessoais" obtiveram os maiores percentuais de satisfação(13). Por isso, o cuidado e o respeito devem direcionar a assistência à saúde, refletindo na satisfação dos doentes e seus familiares.

Outro estudo realizado em Montes Claros-MG, com 319 indivíduos atendidos pela ESF, demonstrou uma percepção positiva dos entrevistados sobre as dimensões da satisfação relacionadas à confiabilidade, sendo identificado que o comportamento da equipe de saúde inspirava confiança nos usuários. A responsabilização do profissional para com o estado de saúde do indivíduo constitui-se como um dos elementos essenciais de um efetivo atendimento. Além disso, desperta no usuário um sentimento de confiança em relação ao profissional que presta a assistência ${ }^{(14)}$.

Outros familiares valorizaram o fato de que atualmente o atendimento é prestado, independente da pessoa estar ou não em seu município de residência, favorecendo assim a continuidade do tratamento e recebimento da assistência.

Ele ia direto no postinho, pegava os remédios, fazia as consultas, os exames. Isso de mês em mês, e se ele não passava bem ia também. Sempre ele tinha medicação. Era assim, se ele tivesse em Araruna ele ia no postinho lá, quando estava trabalhando em Goioerê, ele ia lá em Goioerê e sempre era bem atendido (Esposa).

O princípio da integralidade representa, hoje, o maior desafio nas práticas assistenciais e na organização do sistema de saúde. Seu conceito remete obrigatoriamente ao de integração de serviços, formando redes assistenciais, reconhecendo a interdependência dos atores e serviços envolvidos, em face a constatação de que nenhum deles dispõe da totalidade dos recursos e competências necessárias para a solução dos problemas de saúde de uma população em seus diversos ciclos de vida ${ }^{(15)}$. No âmbito das práticas assistenciais, a integralidade deve ser pensada como uma ferramenta para organizar o cuidado em saúde com uma visão holística dos sujeitos ou como ações de atendimento integral de demandas e necessidades, sendo a ESF um forte agente facilitador para a construção deste modelo de atenção(16).

A concretização de um sistema que proporcione um acesso sem barreiras entre os diversos níveis de atenção, do domicílio ao hospital, dos generalistas aos especialistas, do setor público para o privado e que ultrapassem de fato as barreiras municipais, com a otimização de recursos e ampliação das oportunidades de cuidado, ainda é difícil dentro do SUS(15). Porém, neste estudo pode-se perceber o início da modificação deste paradigma, em que o usuário foi atendido em suas necessidades independentemente da sua localidade, se caracterizando como um grande avanço para o setor saúde.

(Des)qualificadores da assistência da atenção básica: perspectiva da família

Grande parte dos entrevistados apontou falhas no acompanhamento realizado pela equipe da ESF. Para alguns, o fato das visitas domiciliares serem realizadas apenas pelos Agentes Comunitárias de Saúde (ACS), sem a presença do médico, refletia negativamente na qualidade da assistência. Por vezes, o atendimento prestado pelos ACS sequer foi considerado como uma forma de acompanhamento, como se observa na fala a seguir:

Fala que tem saúde da família, porque fala que tem, que eles passam na casa, mas aqui para nós, isso não vigorou não! Só as moças da saúde mesmo, mas médico acompanhando, não tem não (Esposa).

No imaginário de grande parte da população, apesar da equipe da ESF ter caráter multiprofissional, ainda se apreende o profissional médico como o maior detentor de conhecimento e o único responsável pela assistência, pois para muitos usuários dos serviços de saúde a representação social do processo saúde-doença é feita, em última instância, pela prática médica, na qualidade de saber dominante no campo da organização das práticas de saúde. Isto torna, em muitos casos, o relacionamento entre médico-paciente unidirecional e autoritário, visto que, o saber científico se apresenta como única e verdadeira forma para o alcance eficaz do tratamento e da prevenção(17). 
Diante desta situação, acredita-se que a organização do processo de trabalho em saúde necessita modificar o seu foco, passando de centrado nas ações do médico/profissional, para centrado no usuário, devendo este novo prisma ser incorporado na dinâmica dos processos de atenção à saúde nos serviços, ou seja, o usuário ao exercer os seus direitos de acesso universal, sai da condição de mero expectador e se transforma em sujeito autônomo, acordando sua terapêutica com os profissionais de saúde, o que leva a uma maior tendência de adesão ao tratamento ${ }^{(18)}$.

Vale ressaltar que a implantação da ESF por si só não garante a modificação do modelo assistencial médico-centrado. Depende, na realidade, da mudança na forma de se produzir o cuidado, assim como no modo de agir dos profissionais entre si e com os usuários ${ }^{(17)}$. Uma das alternativas seria valorizar a atuação de profissionais com uma visão integral do indivíduo e com formação para atuar junto à comunidade, em contraposição ao modelo baseado na especialização do atendimento.

Essa visão fragmentada do ser humano é resultado de um paradigma biologicista que durante muito tempo perdurou, no entanto com o advento dos programas de humanização no SUS há uma tendência de quebra deste modelo, mas isso somente acontecerá se cada um, profissionais e clientes, perceber a unicidade que existe dentro do ser humano, gerando respeito mutuo e aceitação de mudanças, como por exemplo, que a equipe se complementa com seus diferentes saberes e práticas.

Apesar de a ESF destacar a importância de se desenvolver ações em uma perspectiva de atenção integral à família, e da visita domiciliar, citada acima, ser um instrumento de intervenção fundamental, por priorizar o diagnóstico de problemas dentro da realidade dos indivíduos, nenhum dos entrevistados relatou qualquer tipo de atividade que valorizasse este novo paradigma. Todas as ações desenvolvidas pela equipe eram direcionadas apenas ao indivíduo doente, embora várias famílias possuíssem outros integrantes com DC, principalmente a HA.

Os profissionais atendiam no posto. Só tinha um médico que tratava dela no posto, só que ele não falava nada para a gente, só dava o remédio mesmo (Irmã).

Eles vinham aqui e perguntavam do meu irmão, se ele estava bem. Nunca perguntaram sobre mim, nunca verificaram minha pressão (Irmã).
A assistência às pessoas com HA requer por parte da equipe de saúde atenção especial no tocante à problemática do controle pressórico, que por sua vez apresenta estreita relação com a forma como o indivíduo e sua família são assistidos por médicos, enfermeiros, técnicos e auxiliares em enfermagem na atenção básica. A pessoa hipertensa e seus familiares devem estar devidamente orientados sobre o curso prolongado da doença, suas especificidades e tratamento, para que possam participar do controle efetivo dos fatores de risco que agravam o quadro clínico ${ }^{(19)}$.

Outro fator percebido pelos familiares como indicativo da má assistência foi a demora existente no sistema de saúde, principalmente no que tange aos encaminhamentos para exames e consultas com médicos especialistas:

Só muito depois que ela morreu ligaram do postinho para avisar que o exame que ela tinha feito estava pronto. Dependendo exame demorava muito (Irmã).

A única coisa é que precisava fazer uns exames da perna e da cabeça e não saiu, ele morreu e não saiu... (Nora).

Ele ficava, tinha vez que de um a dois meses esperando uma consulta, e ninguém pode esperar tanto assim (Esposa).

Esta dificuldade levava os familiares a optarem, quando possível, pelo sistema privado para atendimento de seu familiar doente:

Vinham as mulheres do postinho, até que acompanharam bastante, muitos anos, só que depois a gente viu que o negócio de saúde do governo é meio fraco, se precisa de algum tratamento é meio demorado, tinha que esperar muito, aí nós fizemos o plano de saúde, e ela usou muitos anos esse plano (Esposo).

Um estudo realizado na região metropolitana de Curitiba (PR) junto a 12 pessoas com hipertensão demonstrou que as dificuldades de acesso aos serviços de saúde foram representadas pela demora em marcar consultas e exames ou no retorno ao atendimento médico, sendo que esses fatores foram referidos como potenciais desencadeadores da baixa adesão ao tratamento anti-hipertensivo ${ }^{(20)}$.

Um dos informantes entendia que a demora no atendimento está na demanda excessiva que procura a UBS.

Do atendimento deles eu não tenho queixa não, mas o que não podia é ter muita gente lá na unidade, porque demora muito para a gente ser atendido, mas ai a culpa não é deles (Neta). 
Outras pessoas se queixaram especificamente da falta de medicamento de uso contínuo no serviço:

O posto foi bom, fomos bem atendidos, mas às vezes eles falavam assim: "no posto não tem remédio para o seu pai". Aí, quando não tinha, nós comprávamos (Filha).

O SUS tem entre seus princípios a universalidade da oferta de assistência e essa, nas últimas décadas, tem sido a maior responsável pela expansão dos serviços de saúde. No entanto, na prática diária, ainda existem dificuldades que impedem a satisfação das necessidades de assistência à saúde de toda a população. Um dos fatores que contribuem para tal situação é a grande dificuldade de acesso dos indivíduos ao nível secundário da assistência.

Estudo realizado em Recife-PE, com 591 usuários do SUS revelou que dentre todos os aspectos analisados "a disponibilidade de medicamentos" e "o tempo de espera até o atendimento" obtiveram os menores graus de satisfação por parte dos entrevistados ${ }^{(13)}$, o que também pode ser observado no relato dos participantes deste estudo, em que os familiares referiram a demora do atendimento como um dos principais fatores de insatisfação com o serviço de saúde.

Outra situação que precariza o atendimento primário dispensado à população adulta decorre da ineficácia e iniquidade dos serviços de saúde ofertados nos espaços locais de construção das políticas de gestão e de cuidado. Estes fatores representam um dos pontos de estrangulamento para a efetivação das ações de acompanhamento e tratamento da HA nos serviços primários de saúde, associado à não adesão a terapêutica do usuário e práticas profissionais fragmentadas, com base no paradigma biomédico que traz em sua concepção a cura do corpo mediante intervenções focadas na clínica tradicional(21).

Nesta perspectiva, existe a necessidade e o desafio de se ampliar os serviços, melhorar o atendimento à população, diminuir as filas e o tempo de espera, o que inclui necessariamente a (re)estruturação do orçamento setorial, as mudanças na formação dos recursos humanos em saúde que se pautem e apliquem este novo modelo assistencial e de gestores, em todos os níveis que reorientem as políticas públicas e a organização dos serviços de saúde ${ }^{(9)}$.

Além de identificar a demora como um ponto extremamente negativo para o bom funcionamento do sistema, os familiares também se mostraram descontentes com a assistência oferecida pelos profissionais da UBS em decorrência do descaso e dificuldade em agilizar o atendimento em algumas ocasiões:

Ai! Depende do médico, da enfermeira, de cada um lá, se eu pegar os 50\% que é bom, é beleza, mas se pegar os $50 \%$ que é ruim, aío atendimento sai ruim (Esposa).

Olha! Eu acho que falta muita coisa. Eu acho assim, se o médico vê que a pessoa não está se dando bem com o remédio, deveria trocar! Se não está bem, o médico tem que dar um remédio melhor (Esposa).

[...] eles atendiam tão mal. Tinha vez que a pressão dele ficava alta, e ele ia no posto medir, chegava lá e falava: "mede a minha pressão que está alta". Mediam, mas só que demorava, tinha vez que ele não tinha paciência e vinha embora sem medir(Filha).

Por vezes, alguns entrevistados culparam a equipe de saúde pela demora no atendimento, e consequentemente pelo agravamento do caso e óbito do familiar:

Era uma "enrolação". Se um tiver que morrer, morre. A minha mãe morreu por descuido mesmo, porque foi chamar um carro e até vir o carro, não deu nem tempo de chegar o médico. Eu acho que demora muito (Filha).

O atual descuidado com a saúde gera um excesso de encaminhamentos para especialistas e alto consumo de exames, tornando os serviços pouco resolutivos, pois a assistência, desse modo, se torna incapaz de dar vazão à população que procura os serviços de saúde ${ }^{(13)}$. Prevalece então, um processo de trabalho partilhado que desconhece o sujeito pleno, cujo qual traz consigo, além de um problema de saúde, uma intensa subjetividade, uma história de vida, que podem ser também considerados como determinantes de agravos.

Além das dificuldades ligadas à gestão do SUS, alguns relatos mostram com clareza a percepção dos familiares quanto a falta de atenção e acolhimento por parte dos profissionais que os atendem. Isto provavelmente ocorre porque para os usuários, o cuidado/assistência significa mais do que simplesmente atender e/ou executar procedimentos técnicos. Significa cuidar do emocional também:

Eu acho, que ainda falta um pouco mais de atenção, de buscar mais detalhes, não ficar só na carteirinha, observar os pacientes, essas coisas, porque a carteirinha não vai dizer na verdade como 
ele está, eu acho que precisa de mais atenção, alguns atendem muito correndo (Irmão). Quando é para correr, não corre... O dia que ele teve derrame cerebral demorou 15 minutos para uma ambulância chegar(Esposa).

Não era muito bom, eles mediam a pressão certinho, só que a mulher era muito rabugenta (Irmã).

Esta concepção sobre o tipo de cuidado que a população esperava receber do serviço vem ao encontro daquela concebida teoricamente pela enfermagem a qual coloca o cuidar, como respeitar os indivíduos na sua integralidade, oferecendo-lhe assistência qualificada, compartilhando ações humanas de zelo, desvelo e solidariedade. Contudo, nem sempre isto é colocado em prática.

Ademais, pode-se observar que outros familiares tem verdadeiro desconhecimento sobre o atendimento oferecido pela equipe de saúde, seja porque não houve uma continuidade da assistência, ou porque apesar de ser próximo o familiar não se interessava em conhecer como era fornecida as orientações a sua esposa:

Antes de ela morrer, passava o negócio de saúde da família para fazer o cartão, não sei direito, mas eles nunca deram esse cartão também, nem nada (Esposo).

Ah... não sei, eles conversavam só com ela!(Esposo).

Este fato nos leva a refletir sobre duas possibilidades: uma que seria a falha na assistência, à medida que a mesma é centrada no indivíduo doente, não estendendo as orientações aos demais familiares, e a outra é a de que o entrevistado não teve interesse em acompanhar e conhecer o tratamento de saúde proposto a seu membro familiar. Por sua vez, diferentemente do evidenciado nesta fala, estudos demonstram que os familiares que apresentam mais interesse e preocupação em proporcionar bem-estar aos seus familiares doentes, bem como os que buscam melhores condições de cuidado para seu membro familiar, são aqueles que na relação doente-cuidador se revelam como pais-filhos ou cônjuges ${ }^{(22)}$.

O eficaz controle da HA depende diretamente da adesão do cliente ao tratamento, do envolvimento de toda a família e da qualidade do atendimento dos profissionais envolvidos na assistência, garantindo informação e suporte necessário para cada caso, constituindo pré-requisitos fundamentais quando se pretende avançar na integralidade da atenção prestada e no controle da mortalidade por doenças cardíacas e cerebrovasculares ${ }^{(23)}$.
Uma das dificuldades encontradas no atendimento às pessoas com hipertensão é a falta de adesão ao tratamento, o que tem constituído um grande desafio para os profissionais que as acompanham, e possivelmente tem sido responsável pelo aumento dos custos sociais com absenteísmo ao trabalho, licenças para tratamento de saúde e aposentadorias precoces $^{(18)}$. Destarte, os profissionais de enfermagem necessitam buscar formas de tentar fidelizar a pessoa com HA ao seu tratamento, o que é possível quando se conhece as reais causas que interferem no processo de aderência à terapêutica e também quando se insere a família nas atividades de planejamento e gerenciamento do mesmo.

No entanto, para se conhecer as reais necessidades do cliente é preciso estabelecer uma relação de confiança, um acolhimento eficaz, conhecer sua realidade, pois somente assim ele compreenderá a necessidade de participar do seu plano terapêutico, já que durante muito tempo ele esteve afastado, tendo sempre o médico/profissional decidindo por ele e, quando é convidado a participar, se não tiver confiança e empatia junto ao profissional, não terá bases suficientes para realizar tal atividade com segurança ${ }^{(9,14)}$.

Outra situação preocupante evidenciada no presente estudo foi a lacuna encontrada no serviço de saúde relacionado ao atendimento à família após o óbito do paciente acometido pela HA. Neste aspecto verifica-se que as famílias não receberam nenhuma visita da equipe da ESF no período de luto, o qual normalmente é marcado por desequilíbrio e uma série de dificuldades sentida por todos os familiares. Esse fato nos faz refletir mais uma vez que a atuação da equipe de saúde junto à família é apenas em virtude da doença, ou seja, mesmo com a mudança do modelo assistencial, a doença ainda é o centro da atenção, inexistindo um acompanhamento integral a todos os membros e nas diversas fases vivenciadas pela família, talvez até mesmo pela limitação dos profissionais em acompanhá-los nesse momento.

Minha esposa morreu e acabou, ai ninguém apareceu mais (Esposo).

Eu não me lembro de nenhuma visita depois da morte dele, eu não me lembro (Esposa).

Entre os que referiram ter recebido a visita dos integrantes da ESF, em nenhum momento referiram que o foco foi o luto:

Depois que ele morreu, a ACS de vez em quando vem aqui falar com a minha sobrinha. Vem para olhar as crianças, ver se está 
levando as crianças para pesar, esse negócio de bolsa família. Veio quando o meu irmão estava muito ruim e depois que faleceu não veio mais (Irmã).

A relação profissional-familiares é muito importante no momento do diagnóstico, ao longo do tratamento e também no processo de luto. O contato com a família após a morte do paciente que estava sendo acompanhado pelo serviço de saúde torna-se essencial, pois permite falar sobre a pessoa que morreu, trabalhar eventuais dúvidas que surgem (se foi feito tudo que devia/poderia ser feito), ajudando a família a compreender e aceitar melhor o processo da morte.

Assim, seria útil um serviço de apoio a toda a família, na forma de grupos de ajuda mútua, tanto para aqueles que se sentem em posição de cuidar, quanto para aqueles que necessitem de aconselhamento. Os grupos de apoio auxiliam a pessoa que sofreu a perda, a compreender melhor a situação vivenciada ${ }^{(24)}$. Além disso, é importante lembrar que a família enlutada não sofre somente o óbito de seu ente querido, mas também a quebra do convívio com pessoas que faziam parte de sua convivência. Sendo assim, é importante que a equipe continue a realizar assistência a família, por meio da visita domiciliar.

O acompanhamento das famílias nas quais ocorreu a morte de um de seus membros é necessário e precisa ser compartilhado e convergir com o trabalho dos demais profissionais de saúde, uma vez que é na equipe multidisciplinar que ocorre a interação, a troca de conhecimentos e a construção de novos saberes, ou seja, a soma de esforços para construção de uma abordagem qualificada para assistir as pessoas que perderam um ente querido ${ }^{(24)}$.

\section{CONSIDERAÇÕES FINAIS}

Evidenciou-se que as famílias percebem a assistência da atenção básica ao paciente com HA, principalmente por meio das visitas domiciliares realizadas pela equipe da ESF, e que valorizam esta atividade especialmente quando é realizada com a presença do médico. No entanto, percebem também muitas falhas na assistência prestada, representadas, por exemplo, pela demora nos encaminhamentos para consultas e exames especializados.

Outro nó crítico percebido pelos familiares foi o fato da assistência ser centrada no doente e nos cuidados necessários para o controle da $\mathrm{HA}$, desta forma pode ser verificado que, por mais que existisse uma equipe multiprofissional de saúde que acompanhasse a família, por meio de visitas domiciliares, ainda não havia sido incorporado os princípios da ESF na prática de trabalho das equipes, enquanto um modelo que visa à assistência familial, à integralidade e as ações de promoção da saúde e prevenção de agravos.

Uma situação preocupante percebida foi que em nenhum dos relatos houve referência à presença do enfermeiro nas visitas domiciliares, demonstrando que este profissional, talvez por excesso de carga de trabalho ou mesmo por despreparo ou desinteresse, não se faz reconhecer pela população. Além disso, outro achado alarmante é que nenhuma das famílias em estudo recebeu qualquer tipo de assistência após o óbito do familiar, visando o apoio e conforto para o luto da família, demonstrando haver a necessidade de uma readequação do pensamento e do modo de agir das equipes da ESF em relação aos familiares enlutados.

Alguns pontos positivos em relação à assistência também foram citados, como por exemplo, a possibilidade de continuidade do tratamento independentemente da localidade que o indivíduo esteja. Nesta perspectiva, se no âmbito da atenção básica o tratamento se faz eficaz, evita-se complicações e consequentemente diminui-se a procura e os encaminhamentos ao nível terciário, onerando menos o setor da saúde pública e atenuando o desgaste físico e mental dos pacientes e seus familiares.

Uma das limitações encontradas foi a dificuldade de compreender a assistência em diferentes municípios com portes populacionais diversos, uma vez que cada município implementa os programas ministeriais a seu modo. Porém, acredita-se que os resultados do estudo poderão contribuir na definição de ações, estratégias e programas a serem adotados nos serviços de saúde, com vistas à promoção da saúde e prevenção de doenças, pois a partir dos relatos da família, os pontos-chaves em que a atuação da atenção básica não está contemplando seus pressupostos, foram evidenciados, contribuindo assim para que gestores e profissionais de saúde possuam atuar de acordo com as necessidades encontradas. Por fim, considera-se que a assistência profissional deve buscar a integralidade das ações, sem esquecer que o ser humano possui costumes, crenças e valores que são influenciados pelas interações sociais, inclusive com os profissionais de saúde. 


\section{REFERÊNCIAS}

1. Oliveira JCA, Tavares DMS. Atenção ao idoso na estratégia de Saúde da Família: atuação do enfermeiro. Rev Esc Enferm USP. 2010;44(3):77481.

2. Martins JJ, Albuquerque GL, Nascimento ERP, Barra DCC, Souza WGA, Pacheco WNS. Necessidades de educação em saúde dos cuidadores de pessoas idosas no domicílio. Texto Contexto Enferm. 2007;16(2):254-62.

3. Miranzi SSC, Ferreira FS, Iwamoto HH, Pereira GA, Miranzi MAS. Qualidade de vida de indivíduos com diabetes mellitus e hipertensão acompanhados por uma equipe da saúde da familia. Texto Contexto Enferm. 2008;17(4):672-79.

4. Sociedade Brasileira de Cardiologia; Sociedade Brasileira de Hipertensão; Sociedade Brasileira de Nefrologia. VI Diretrizes Brasileiras de Hipertensão. Arq Bras Cardiol 2010;95(1 Supl 1):1-51.

5. Pereira M, Lunet N, Azevedo A, Barros H. Differences in prevalence, awareness, treatment and control of hypertension between developing and developed countries. J Hypertens. 2009;27(5):963-75.

6. Portal da Saúde [Internet]. Brasília: Ministério da Saúde (BR) [acesso em: 30 mar 2013]. Hipertensão arterial atinge 23,3\% dos brasileiros. Disponível em:

http://portal.saude.gov.br/portal/aplicacoes/noticias/default.cfm?pg=d spDetalheNoticia\&id area=124\&CO NOTICIA=12485.

7. Baptista EKK, Marcon SS, Souza RKT. Avaliação da cobertura assistencial das equipes de saúde da família às pessoas que faleceram por doenças cerebrovasculares em Maringá, Paraná, Brasil. Cad Saude Publica. 2008;24(1):225-29.

8. Ministério da Saúde. Plano de Reorganização da Atenção à Hipertensão Arterial e ao Diabetes mellitus: manual de hipertensão arterial e diabetes mellitus. Brasília: Ministério da Saúde; 2001. 9. Rosa WAG, Labate RC. Programa saúde da família: a construção de um novo modelo de assistência. Rev Latino-Am Enfermagem. 2005;13(6):1027-34.

10. Bardin L. Análise de conteúdo. Lisboa: Editora 70; 2008. 11. Costa JMBS, Silva MRF, Carvalho EF. Avaliação da implantação da atenção à hipertensão arterial pelas equipes de Saúde da Família do município do Recife (PE, Brasil). Cienc Saude Colet. 2011;16(2):623-3. 12. Santos EM, Kirschbaum DIR. A trajetória histórica da visita domiciliária no Brasil: uma revisão bibliográfica. Rev. Eletr. Enf. [Internet]. 2008 [acesso em: 30 mar 2013];10(1):220-7. Disponível em: http://www.fen.ufg.br/fen revista/v10/n1/v10n1a20.htm.

13. Gouveia GC, Souza WV, Luna CF, Szwarcwald CL, Souza Júnior PRB. Satisfação dos usuários com a assistência de saúde no estado de Pernambuco, Brasil, 2005. Cienc Saude Colet. 2011; 16(3):1849-61. 14. Dias OV, Vieira MA, Dias JP, Ramos LH. As dimensões da satisfação dos usuários do Programa Saúde da Família: confiabilidade e empatia. Acta Paul Enferm. 2011;24(2):225-31.

15. Hartz ZMA, Contradriopolus AP. Integralidade da atenção e integração de serviços de saúde: desafios para avaliar a implantação de um “Sistema sem muros". Cad Saude Publica 2004; 20 (Supl. 2):331-53. 16. Silva RVGO, Ramos FRS. Integralidade em saúde: revisão de literatura. Ciênc. cuid. saúde [Internet]. 2010 [acesso em: 30 mar 2013]; 9(3):593-601. Disponível em:

http://dx.doi.org/10.4025/cienccuidsaude.v9i3.8726.

17. Tesser CD, Poli Neto P, Campos GWS. Acolhimento e (des)medicalização social: um desafio para as equipes de saúde da família. Cienc Saude Colet. 2010; 5 (Supl. 3):3615-24.

18. Gusmão JL, Ginani GF, Silva GV, Ortega KC, Mion Junior D. Adesão ao tratamento em hipertensão arterial sistólica isolada. Rev. bras. hipertens [Internet]. 2009 [acesso em: 30 mar 2013];16(1):38-43. Disponível em: http://departamentos.cardiol.br/dha/revista/16-1/11adesao.pdf.

19. Silva SSBE, Colósimo FC, Pierin AMG. O efeito de intervenções educativas no conhecimento da equipe de enfermagem sobre hipertensão arterial. Rev Esc Enferm USP. 2010;44(2):488-96. 20. Maciel KF, Ulbrich EM, Labronici LM, Maftum MA, Mantovani MF, Mazza VA. A hipertensão arterial na percepção dos seus portadores. Ciênc. cuid. saúde [Internet]. 2011 [acesso em: 30 mar 2013];10(3):437-
43. Disponível em:

http://dx.doi.org/10.4025/cienccuidsaude.v10i3.10845.

21. Araújo JL, Paz EPA, Moreira TMM. Hermenêutica e o cuidado de saúde na hipertensão arterial realizado por enfermeiros na estratégia saúde da família. Esc Anna Nery Enferm. 2010;14(3): 560-6.

22. Brondani CM, Beuter M, Alvim NAT, Szareski C, Rocha LS. Cuidadores e estratégias no cuidado ao doente na internação domiciliar. Texto Contexto Enferm 2010;19(3):504-10.

23. Oshiro ML, Castro LLC, Cymrot R. Fatores para não-adesão ao programa de controle da hipertensão arterial em Campo Grande, MS. Rev. ciênc. farm. básica apl [Internet]. 2010 [acesso em: 30 mar 2013];31(1):95-100. Disponivel em: http://servbib.fcfar.unesp.br/seer/index.php/Cien Farm/article/view/876/939. 24. Santos, EM. Familiares enlutados: compreensão fenomenológica existencial de suas vivências. Texto Contexto Enferm. 2011;20(3):21422.

Artigo recebido em 27/06/2012.

Aprovado para publicação em 06/09/2012.

Artigo publicado em 31/03/2013. 